\title{
Absorption of water and sodium and activity of adenosine triphosphatases in the rectal mucosa in tropical sprue
}

\author{
B S RAMAKRISHNA AND V I MATHAN \\ From The Wellcome Research Unit \& Department of Gastroenterology, Christian Medical College and \\ Hospital, Vellore, India
}

SUMMARY In 10 southern Indian patients with tropical sprue, in vivo dialysis showed a defect of absorption of water and sodium from the rectum, when compared with 11 healthy volunteers. Sodium-potassium-ATPase activity, measured in homogenates of rectal biopsies, was significantly diminished in patients with sprue. Magnesium-ATPase and alkaline phosphatase were normal in biopsy homogenates. Decreased activity of colonic sodium-potassium-ATPase may contribute to diarrhoea in some patients with tropical sprue.

Decreased water absorption by the colon contributes to diarrhoea, the major symptom of tropical sprue.' It has been suggested that inhibition of colonocyte sodium-potassium-ATPase (Na,K-ATPase) by unsaturated fatty acids may be a factor in the pathogenesis of water malabsorption and diarrhoea in tropical sprue. ${ }^{2}$ There are other chronic diarrhoeal diseases where decreased activity of $\mathrm{Na}, \mathrm{K}$-ATPase may contribute to diarrhoea and fluid loss. These include coeliac disease, ${ }^{3}$ the postenteritis syndrome ${ }^{4}$ chronic undifferentiated diarrhoea of childhood, ${ }^{5}$ and active ulcerative colitis. ${ }^{\circ}$ There are no studies that directly correlate $\mathrm{Na}, \mathrm{K}-\mathrm{ATPase}$ activity with quantitative estimation of water and electrolyte absorption. In this paper the results of a study quantifying rectal absorption of water and electrolytes using the dialysis bag technique, ${ }^{78}$ is correlated with the activity of $\mathrm{Na}, \mathrm{K}$-ATPase in the rectal mucosa.

\section{Methods}

SUBJECTS

Eleven healthy volunteers and 10 southern Indian patients diagnosed to have tropical sprue were

Address for correspondence: Professor V I Mathan, The Wellcome Research Unit and Department of Gastroenterology, CMC Hospital, Vellore 632004, India

Received for publication 6 November 1987. studied. The healthy volunteers were of the same socio-economic group and from a background similar to all other patients. All subjects included in the study were admitted to a metabolic ward, and detailed studies of intestinal structure and function were carried out. ${ }^{9}$ The diagnosis of tropical sprue was established according to standard criteria. ${ }^{911}$ All patients with sprue had diarrhoea of more than three months duration. All had steatorrhoea ranging from 7-22 g/day (mean 14.6 g/day). All had xylose malabsorption, and five of the 10 vitamin $B_{12}$ malabsorption. Absorption parameters were normal in all the healthy volunteers. The study was ethically approved by the Research Committee of this institution.

The subjects were allowed a normal diet during the tests. On the morning of the test, a saline enema was administered to all subjects. Three hours later, a filled dialysis bag was introduced into the rectum, as described by Edmonds.' Eight centimetre long dialysis tubing, of $7 \mathrm{~mm}$ diameter, was knotted at one end and passed over a wire stiffener. It was tied at the end over a rubber spigot. The tubes were filled with $7 \mathrm{ml}$ test solution. The bag was thinly lubricated with xylocaine jelly, weighed and introduced into the rectum. The base of the bag was $2 \mathrm{~cm}$ above the anal verge. The bag was left in position for one hour, during which time the subjects were recumbent. At the end of one hour, the bag was taken out, reweighed, and its contents aspirated by puncture. If there was faecal staining of the solution, that 
particular test was discarded. The contents were immediately frozen and stored at $-20^{\circ} \mathrm{C}$ until analysis. The test solution was of the following composition in (mmol/l) sodium (102), acetate (102), potassium (43), chloride (34), bicarbonate (9), $\mathrm{pH} \mathrm{7 \cdot 8,} \mathrm{osmolality} 290 \mathrm{mOsm} / \mathrm{kg}$.

Two days after the test, allowing time to recover from any morphological effects of the enema, rectal mucosal biopsies were obtained using a TrueloveSalt suction biopsy instrument at a distance of $10 \mathrm{~cm}$ from the anal verge. The biopsies were snap frozen in liquid nitrogen and stored at $-70^{\circ} \mathrm{C}$ for enzyme assays.

Rectal mucosal Na,K-ATPase was directly measured in biopsy homogenates in nine subjects in each group using a modification of the method of Quigley and Gotterer. ${ }^{11}$ Biopsy bits $(25-30 \mathrm{mg})$ were homogenised in $0.4 \mathrm{ml}$ of ice cold sucrose-TrisImidazole (0.25 M, $60 \mathrm{mM}, 60 \mathrm{mM}, \mathrm{pH} 7.0)$ buffer using a Teflon pestle tissue homogeniser (Arthur $\mathrm{H}$ Thomas, Philadelphia, PA) for one minute. Total $\left(\mathrm{Mg}^{++}, \mathrm{Na}^{+}\right.$, and $\left.\mathrm{K}^{+}\right)$stimulated ATPase activity was determined by incubating $100 \mu \mathrm{l}$ of the above homogenate in a medium ( $1.5 \mathrm{ml}$ final volume $)$ containing (in mmol/l) Tris-Imidazole buffer (30), $\mathrm{NaCl}(120)$, $\mathrm{KCl}(20), \mathrm{MgC1} 2$ (10), and disodium ATP (6) (Sigma $\mathrm{UK}$, specification No A5394) for 20 minutes at $37^{\circ} \mathrm{C}$. The incubation was stopped by adding $0.5 \mathrm{ml}$ of trichloroacetic acid $(46 \% \mathrm{v} / \mathrm{v})$. After centrifugation at $2000 \mathrm{~g}$, the inorganic phosphate liberated to the supernatant was determined. ${ }^{12}$ Magnesium-ATPase activity was determined in a similar medium containing $1 \mathrm{mM}$ ouabain. In each assay a blank containing reagents, to which homogenate was added after adding trichloroacetic acid, was included. $\mathrm{Na}, \mathrm{K}-\mathrm{ATPase}$ activity was calculated by subtracting the $\mathrm{Mg}^{++}$-stimulated ATPase from the total ATPase activity. Protein was determined according to Lowry et $a l^{13}$ using bovine serum albumin as standard. $\mathrm{Na}, \mathrm{K}$-ATPase activity was expressed in terms of $\mu$ moles of inorganic phosphate liberated $/ \mathrm{mg}$ protein/ hour. Alkaline phosphatase activity of the rectal mucosa was also measured directly in biopsy homogenates in eight controls and nine patients with sprue, using p-nitrophenyl phosphate as a substrate. One hundred microlitres of the homogenate was incubated with $0.4 \mathrm{ml}$ of medium containing (final concentration $\mu \mathrm{mol} / \mathrm{l})$ : Tris- $\mathrm{HCl}$ buffer $(50, \mathrm{pH} 9 \cdot 0)$. p-nitrophenyl phosphate $(0.5)$, and magnesium chloride $(0 \cdot 5)$, for 15 minutes at $37^{\circ} \mathrm{C}$. The reaction was stopped by adding $2.5 \mathrm{ml}$ of $1 \mathrm{M} \mathrm{NaOH}$ and the extent of hydrolysis determined spectrophotometrically. ${ }^{14}$ One unit of activity was taken as the amount of enzyme required to liberate $1 \mu \mathrm{mol}$ of inorganic phosphate/hour, and the specific activity was expressed as milliunits/mg protein.

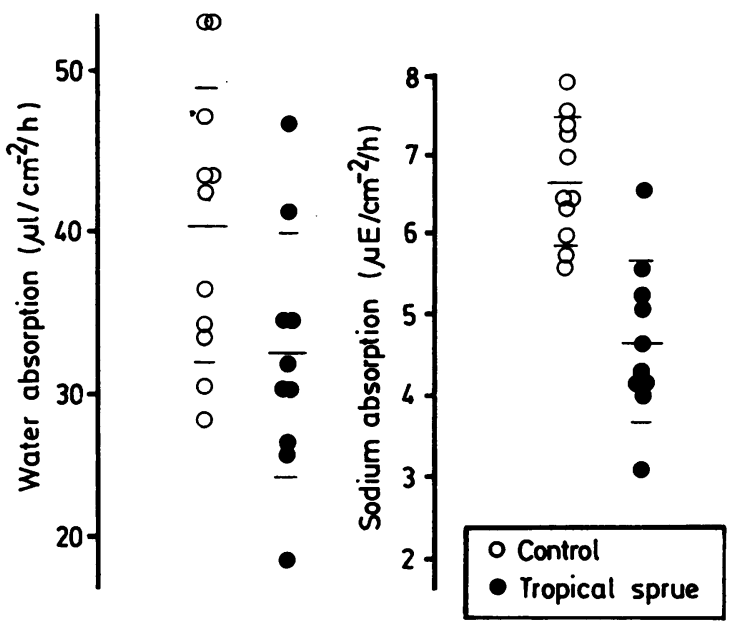

Fig. 1 Absorption of water and sodium from the rectum in control subjects $(\mathrm{O})$ and in patients with tropical sprue (O).

Sodium and potassium were determined by flame photometry and chloride and bicarbonate by chemical titration. Acetate was quantified by gas liquid chromatography on $20 \%$ Neopentyl-glycolsuccinate on Gas Chrom Q 80-100 mesh, in a PYE series 104 chromatograph, using a flame ionization detector. Absorption of water, sodium, potassium and acetate was calculated according to standard formulae and expressed per $\mathrm{cm}^{2}$ of the surface area of the dialysis bag. ${ }^{7}$ Statistical analysis was carried out on all data using the Student's $t$ test.

\section{Results}

In healthy volunteers the mean rectal water absorption was $40 \mu \mathrm{l} / \mathrm{h} / \mathrm{cm}^{-2}$ (SE 8.5). It was significantly lower $(\mathrm{p}<0.05)$ in patients with tropical sprue with a mean of $32.4 \mu \mathrm{l} / \mathrm{h} / \mathrm{cm}^{-2}$ (SD 7.7) (Fig. 1). The absorption of sodium from the rectum was also significantly lower in patients with sprue $4.72(0.98)$ $\mu \mathrm{E} / \mathrm{h} / \mathrm{cm}^{-2}$ compared with the healthy volunteers 6.72 $(0.77) \mu \mathrm{E} / \mathrm{h} / \mathrm{cm}^{-2} \quad(\mathrm{p}<0.01)$. The absorption of acetate was lower in patients with sprue, compared to the controls but the difference was not statistically significant.

Sodium-potassium-ATPase activity in the rectal mucosa in healthy volunteers $[2 \cdot 13(0 \cdot 53) \mu \mathrm{mol} \mathrm{pi} / \mathrm{mg}$ protein/h] was significantly higher than that found in patients with tropical sprue $[1.26(0.26) \mu \mathrm{mol} \mathrm{pi} / \mathrm{mg}$ protein/h] $(\mathrm{p}<0.01)$ (Fig. 2). Sodium absorption did not correlate significantly $(\mathrm{r}=0.425)$ with rectal mucosal sodium-potassium-ATPase activity. Magnesium stimulated ATPase activity was similar in healthy volunteers and in patients with tropical sprue 


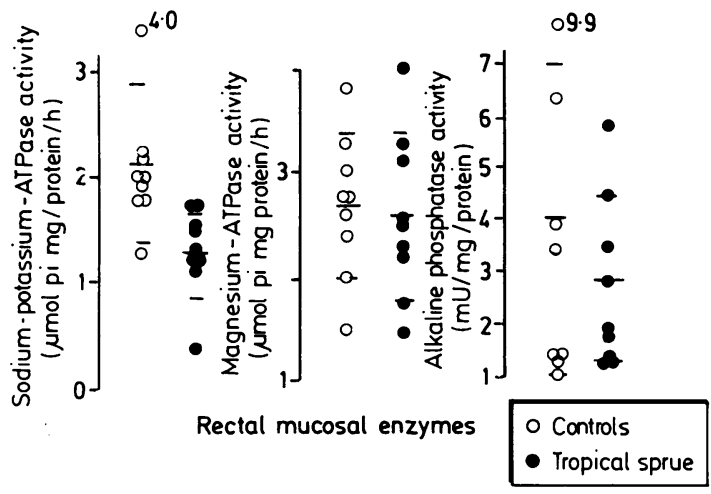

Fig. 2 Activity of sodium-potassium-ATPase, magnesiumATPase and alkaline phosphatase in the rectal mucosa in control subjects $(\mathrm{O})$ and in patients with tropical sprue (O).

(Fig. 2). Alkaline phosphatase activity in the rectal mucosa was slightly depressed in patients with tropical sprue $[2 \cdot 8(1 \cdot 6) \mathrm{mU} / \mathrm{mg}$ protein] compared with the healthy controls [4 (3) $\mathrm{mU} / \mathrm{mg}$ protein]. This difference, however, was not statistically significant.

\section{Discussion}

The present study shows a defect in the absorption of water and sodium by the rectal mucosa in tropical sprue. These results confirm that the defective colonic absorption of water in sprue' can be studied by using the simple technique of quantitating rectal sodium and water absorption. Compared with in vivo colonic perfusion, the dialysis bag technique of quantifying absorption by the rectal mucosa has several advantages. It is easy to do and is well tolerated by the subject. Because it studies absorption from a defined area, relationships between absorption and structural or functional changes in the mucosa can be assessed more easily.

The enzyme sodium-potassium-ATPase may play a role in water and electrolyte absorption from the intestine as it is the biochemical equivalent of the sodium pump. In vivo inhibition of this enzyme with ouabain produces intestinal secretion of water and sodium. ${ }^{15} \mathrm{Na}, \mathrm{K}$-ATPase activity is diminished in the jejunal mucosa of patients with coeliac disease,${ }^{3}$ the postenteritis syndrome, ${ }^{4}$ and chronic undifferentiated diarrhoea of childhood. ${ }^{5}$ In active ulcerative colitis diminished activity of this enzyme has been reported in the colonic mucosa ${ }^{6}$ The present study shows that $\mathrm{Na}, \mathrm{K}$-ATPase activity is diminished in patients with tropical sprue.

Although there was a tendency towards correlation between rectal sodium absorption and
$\mathrm{Na}, \mathrm{K}$-ATPase activity, this was not statistically significant $(r=0 \cdot 425)$. This poor correlation probably reflects the small amount of tissue obtained at biopsy, which may not accurately represent the total $\mathrm{Na}, \mathrm{K}$-ATPase activity of the mucosa in contact with the dialysis bag.

Colonocyte damage is demonstrable in the rectal mucosa of patients with tropical sprue (Mathan unpublished observations). The reduction of $\mathrm{Na}$,K-ATPase is unlikely to be solely the result of colonocyte damage as the two other colonocyte enzymes estimated, magnesium ATPase and alkaline phosphatase, were not significantly reduced in the patients with sprue. In coeliac disease and the postenteritis syndrome replacement of surface enterocytes by more immature cells as indicated by reduction of alkaline phosphatase is considered to be the reason for the reduction in $\mathrm{Na}, \mathrm{K}$-ATPase activity. ${ }^{34}$ In the present study alkaline phosphatase activity was not significantly reduced. It has been suggested that prostaglandins may be responsible for the reduction in Na, K-ATPase activity in ulcerative colitis. ${ }^{6}$ We have shown earlier ${ }^{2}$ that faecal free fatty acids are increased in tropical sprue and that colonic water absorption is inversely correlated to the faecal free unsaturated fatty acid content. ${ }^{16}$ It would therefore appear that the functional defect in water and electrolyte absorption by the large bowel is the result of colonocyte damage and the inhibition of $\mathrm{Na}, \mathrm{K}-\mathrm{ATPase}$ by the excess free unsaturated fatty acid content of the faeces in this disease.

The Wellcome Research Unit is supported by the Wellcome Trust, London.

\section{References}

1 Ramakrishna BS, Mathan VI. Water and electrolyte absorption by the colon in tropical sprue. Gut 1982; 23: 843-6.

2 Tiruppathi C, Balasubramanian KA, Hill PG, Mathan VI. Faecal free fatty acids in tropical sprue and their possible role in the production of diarrhoea by inhibition of ATPases. Gut 1983; 24: 300)-5.

3 Tripp JH, Manning JA, Muller DRP, et al. Mucosal adenylate cyclase and sodium-potassium-adenosine triphosphatase in jejunal biopsies of adults and children with coeliac disease. In: McNicholl B, McCarthy CF, Fottrell PF, eds. Perspectives in coeliac disease. Lancaster: MTP Press, 1978: 461-9.

4 Tripp JH, Muller DRP, Harries JT. Mucosal $\mathrm{Na}^{+} \mathrm{K}^{+}$ATPase and adenylate cyclase activities in children with toddler diarrhoea and the postenteritis syndrome. Paediatr Res 1980; 14: 1382-6.

5 Candy D, Larcher VF, Cameron DJS, et al. Lethal familial protracted diarrhoea. Arch Dis Childh 1981; 56: 15-23. 
6 Rachmilewitz D, Karmeli F, Sharon P. Decreased colonic $\mathrm{Na}^{+} \mathrm{K}^{+}$ATPase activity in active ulcerative colitis. Israel J Med Sci 1984; 20: 681-4.

7 Edmonds CJ. Absorption of sodium and water by human rectum measured by a dialysis method. Gut 1971 ; 12: $356-62$.

8 McNeil NI, Cummings JH, James WPT. Short chain fatty acid absorption by the human large intestine. Gut 1978; 19: 819-22.

9 Baker SJ, Mathan VI. Tropical sprue in southern India. In: Tropical sprue and megaloblastic anaemia. A Wellcome Trust collaborative study. London: Churchill Livingstone, 1971: 189-261.

10 Klipstein FA, Baker SJ. Regarding the definition of tropical sprue. Gastroenterology 1970; 58: 717-9.

11 Quigley JP, Gotterer SG. Distribution of $\mathrm{Na}^{+} \mathrm{K}^{+}-$ stimulated ATPase activity in rat intestinal mucosa. Biochim Biophys Acta 1969; 173: 456-68.

12 Fiske $\mathrm{CH}$, Subba Row Y. The colorimetric determination of phosphorus. J Biol Chem 1925; 66: 375-400.

13 Lowry OH, Rosbrough NJ, Farr AL, Randall RJ. Protein measurement with phenol reagent. J Biol Chem 1951; 193: 265-75.

14 Thambidorai D, Bachhawat BK. Purification and properties of brain alkaline phosphatase. J Neurochem 1977; 29: 503-12.

15 Charney AN, Donowitz M. Functional significance of $\mathrm{Na}^{+} \mathrm{K}^{+}$ATPase: in vivo ouabain inhibition. Am J Physiol 1978; 234: E629-36.

16 Ramakrishna BS, Mathan VI. The role of bacterial toxins, bile salts and free fatty acids in colonic water malabsorption in tropical sprue. Dig Dis Sci 1987; 32: 500-5. 